American Journal of Environmental Sciences 7 (3): 248-253, 2011

ISSN 1553-345X

(C) 2011 Science Publications

\title{
Effects of Pollutant Diesel Fuels on Neurobehavioral Performance among Workers in Locomotive Depot
}

\author{
${ }^{1}$ Anuar Ithnin, ${ }^{1}$ Radiah Abu Hasan Shaari, ${ }^{1}$ Mazrura Sahani, \\ ${ }^{2}$ Anuar Mohd Mokhtar, ${ }^{1}$ Azhar Abdul Halim and ${ }^{1}$ Normah Awang \\ ${ }^{1}$ Environmental Health Programme, Faculty of Allied Health Sciences, \\ University Kebangsaan Malaysia, Jalan Raja Muda Abdul Aziz, \\ 50300 Kuala Lumpur, Malaysia \\ ${ }^{2}$ Departmental of Occupational Safety and Health, Tingkat 7, \\ Wisma Consplant 2, Jalan SS16/1, 47500 Subang Jaya, Selangor, Malaysia
}

\begin{abstract}
Problem statement: Diesel fuel contains various combinations of hydrocarbons such as cyclohexane, n-hexane, benzene and toluene which can cause health problems in major exposure of that pollutant in locomotive depots. Studies were conducted to evaluate the exposure towards diesel fuel pollutant and the effect on neurobehavioral performances among workers in locomotive depots. Approach: Method used was questionnaire form and neurobehavioral performances were measured by WHO NCTB test among 17 exposure workers and 17 control workers. Air pollutant measurement was carried out by GilAir Sampler Low flow pump and analyzed using NMAM method 1500 and 1501. Measured diesel fuel pollutant are Total Volatile Organic Compound (TVOC), cyclohexane, n-hexane, benzene and toluene in three sampling point which are Power Generator Car (PGC), Locomotive (LOCO), producer and receiver of diesel fuel (PPD). Impact assessment NCTB neurobehavioral was carried out. Results: Measured result showed that overall mean of concentration for Total Volatile Organic Compound (TVOC) was respectively $1.93 \pm 0.70 \mathrm{ppm}, 1.05 \pm 0.19 \mathrm{ppm}$ and $1.01 \pm 0.17 \mathrm{ppm}$ in PGC, Loco and PPD. Average concentration of cyclohexane, n-hexane, benzene and toluene at PGC, Loco, PPD was respectively $0.11 \pm 0.02,0.01 \pm 0.01,0.15 \pm 0.07,0.02 \pm 0.00,0.01 \pm 0.00,0.01 \pm 0.00$, $0.05 \pm 0.01,0.03 \pm 0.00,0.06 \pm 0.03,0.10 \pm 0.08,0.06 \pm 0.03,0.10 \pm 0.06$. All the pollutants measured did not exceed the permissible level based on USECHH 2000. Test for neurobehavioral performance between exposed workers and control showed there are significant difference for SA test non preferred hand $(\mathrm{p}=0.03, \mathrm{p}<0.05)$ and test PAT1 $(\mathrm{p}=0.01, \mathrm{p}<0.05)$. There are significant relationship between NCTB test such as BVR, SA1, SA2 and PAT1 compared to the factor of age, service period and educational level. Conclusion: This study showed that there are significant correlation between cyclohexane concentration with SA 3 (both sides of hand) with value $r=-0.53, p<0.05$ and benzene with DS test, SA 1 (dominant hand), SA 3(both sides of hand) and respectively with value $r=-0.57$,$0.54,-0.64, \mathrm{p}<0.05$. It can be concluded that exposed workers towards diesel pollutant in locomotive industry affect the neurobehavioral performances which correlate the hand-eye coordination of cognitive function, speed stimulation of motor nerve, visual and memory.
\end{abstract}

Key words: Diesel fuels, neurobehavioral performances, motor nerve, cognitive function, diesel pollutant, Power Generator, Total Volatile Organic Compound (TVOC), Trail Making (TMT), Pursuit Aiming (PAT), locomotive depot

\section{INTRODUCTION}

Fuel consumption diesels nowadays are very widespread mainly in automotive motor and transportation sector. Continuous fuel consumption diesel can contribute to air pollution and can affect human health (Song et al., 2000). Besides that, alternative fuels for diesel engines are becoming increasingly important due to diminishing petroleum reserves and the environmental consequences of exhaust gases from petroleum fuelled engines (Najafi $e t$ al., 2007). With more and more evidence coming to light about the adverse effects of concentrated amounts of $\mathrm{CO}_{2}$ in the atmosphere we would know that we need

Corresponding Author: Anuar Ithnin, Environmental Health Programme, Faculty of Allied Health Sciences, Universiti Kebangsaan Malaysia, Jalan Raja Muda Abdul Aziz, 50300 Kuala Lumpur, Malaysia 
to change the way in which we produce the majority of our energy, i.e., burning of fossil fuels (Ahilan et al., 2009).

Diesel fuel are combination between various hydrocarbon produced by distillation. Diesel fuel industry mostly gained during oil refining process. Generally, diesel fuel contains Volatile Organic Compound (VOC) including organic solvent which usually exist in the internal and external air. It is major air pollutant freed whether from industrial or nonindustrial sectors. By its chemical VOC consist of aliphatic, hydrocarbon, halogen, alcohol, ester and aldehyde (Ming, 2005). This study was conducted to determine the exposed level of diesel fuels pollutant and health effect among exposed workers towards diesel fuels pollutant by using the neurobehavioral performances tests.

\section{MATERIALS AND METHODS}

Study population: Overall, as many as 17 workers working in operational diesel fuel part at depots locomotive. Measured diesel fuel pollutant involved only 15 exposed workers according to DOSH guideline (DOSH, 2000). While neurobehavioral measurement was involved 17 exposed workers and 17 control workers that did not expose towards the diesel fuel which were selected based on random method. Overall workers which included were men and noble Malay.

Procedure: Selected workers in pollutant measurement were required to use Low flow pump for pollutant material sampling. As for neurobehavioral sample, respondents were required to reply questionnaire form prepared which contain information of sociodemographic, all important medical and health related information.

Pollutant measurement: TVOC in-situ sample was carried out while fuel measurement diesel made by using GilAir Sampler Low flow pump. The sample of pollutant concentration was determined by using GC-FID.

WHO symptom's subjective question: Workers also required to reply 'Yes' or 'No' for 37 symptoms-related subjective questions according to WHO NCTB (1986) aim to detect early symptoms of nerve toxicity.

Neurobehavioral core test battery: Neurobehavioral Core Test Battery was used to assess toxicity impact as a result of exposed nerve to diesel fuel pollution by using WHO NCTB series of test 1986. This test was easy and efficient which consist series of test for functional assessment such as reaction to speed hearing memory, manual coordination, speed perceptual motor, vision and stability memory nerve motor. Test are grounded in 'isolate and paper' created by World Health Organization for early detection of nerve toxicity (World Health Organization, 1986). Among series of test that have been conducted such as Simple reaction time (SRT), Digit symbol (DS), Span digit's test namely Digit Forward Test (DFT) and Digit Backward Test (DBT), Benton Visual Retention (BVR), Santa Ana Manual Dexterity (SA), Pursuit Aiming (PAT) and Trail Making (TMT).

Statistical analysis: Collected data, the pollutant of selected diesel fuel concentration and neurobehavioral performances among exposed workers and control group were analyzed by using Statistical Package for the Social Sciences (SPSS) version 16. Among statistical analysis applied in this study were descriptive analysis namely determine average, minimum maximum for concentration of pollutant and neurobehavioral performances for exposed workers. While inference analysis carried out was t-test not double. It is used to compare exposed workers performances and control group. Besides that, correlation test between NCTB test with age, period services and education level. At the same time, correlation test between pollutants of diesel fuels with neurobehavioral performances was carried out.

\section{RESULTS}

Concentration of total organic compound: Figure 1 shows the average concentration of total organic compound (TVOC) in every research station during sampling period. Thickness average range (TVOC) in all three sample station was 1.01-1.93 ppm. Highest average concentration achieved in PGC part is $1.93 \mathrm{ppm}$ while lowest average in PPD part is $1.01 \mathrm{ppm}$. Generally, concentration of TVOC for all three sampling point were very low.

Concentration of pollutant diesel fuels according sampling point: Figure 2 shows the average concentration during the study period. Average range for pollutant studied such as cyclohexane, n-hexane, benzene and toluene during the study period is 0.01 $0.15 \mathrm{ppm}$.

Concentration of diesel fuels pollutant at PGC according to shift work: Table 1 shows average concentration of diesel fuels pollutant at PGC parts according to shift of work. Average range pollutant concentration studied was $0.02-0.15 \mathrm{ppm}$. 
Am. J. Environ. Sci., 7 (3): 248-253, 2011

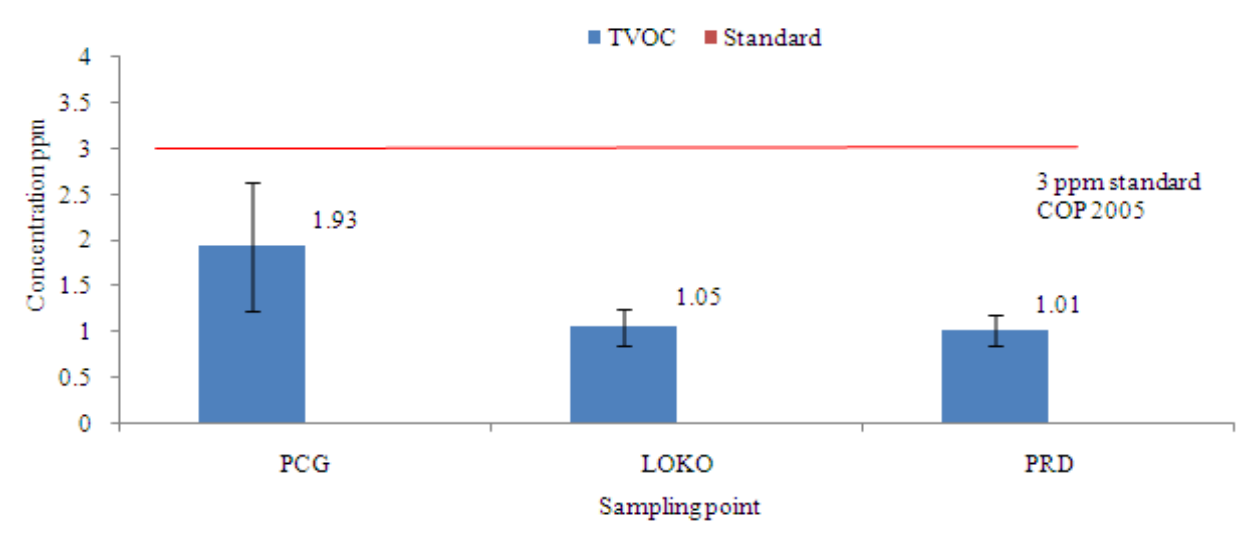

Fig. 1: Average concentration of total VOC each sampling point

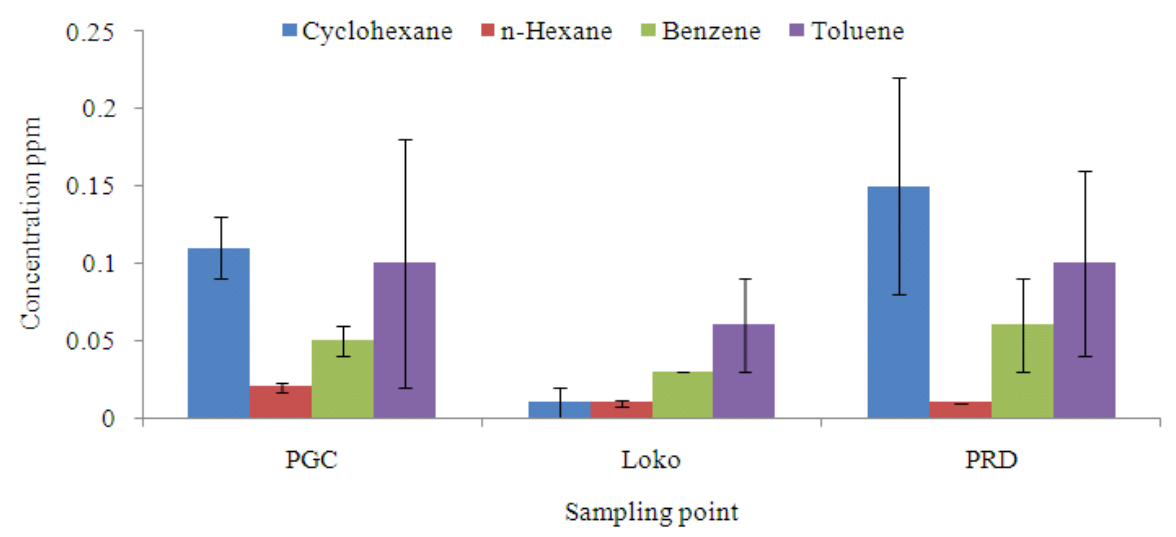

Fig. 2: Average concentration of diesel fuels pollutant according sampling point

Table 1: Average concentration of diesel fuels pollutant at PGC department according shift work

\begin{tabular}{lllll} 
& Concentration, ppm & & & \\
& - & & \\
Shift works & Cyclohexane & n-hexane & Benzene & Toluene \\
\hline Morning & $0.08 \pm 0.03$ & $0.02 \pm 0.00$ & $0.03 \pm 0.01$ & - \\
Evening & $0.09 \pm 0.00$ & - & - & - \\
Night & $0.15 \pm 0.06$ & $0.03 \pm 0.07$ & $0.07 \pm 0.01$ & $0.10+0.01$ \\
\hline
\end{tabular}

\section{DISCUSSION}

Generally, average concentration for all high diesel fuels pollutant in night shift contrasting morning and evening shift. This following diesel oil filling which was more active at night time contrasting morning and evening.Studies found that pollutant received among workers was in low concentration. According to Ming (2005) chronic effects is long run exposure towards air pollutant in low concentration. There is also health effect in low or medium density, where organic compound can cause temporary symptom such as euphoria, headache and vertigo, and prolonged exposure can cause damage on central nervous system including cognitive function and emotion gloom (Guo et al., 2004) and chronic encephalopathy (Triebig and Hallermann, 2001; Saarela et al., 2003).

Concentration of diesel fuels pollutant at Loco department according to shift work: Table 2 shows average concentration diesel fuels pollutant at Loco parts according to shift work. Average range pollutant concentration during study duration was $0.01-0.10 \mathrm{ppm}$.

Concentration of diesel fuels pollutant and standard: Table 3 shows average concentration of diesel fuel pollutant with permitted standard. Average range of pollutant concentration was 0.01-0.15 ppm. 
Am. J. Environ. Sci., 7 (3): 248-253, 2011

Table 2: Average concentration of diesel fuels pollutant at Loco department according to shift work

\begin{tabular}{|c|c|c|c|c|}
\hline \multirow[b]{2}{*}{ Shift works } & \multicolumn{4}{|c|}{ Concentration, ppm } \\
\hline & Cyclohexane & n-hexane & Benzene & Toluene \\
\hline Morning & - & $0.01 \pm 0.00$ & - & $0.10 \pm 0.00$ \\
\hline Evening & - & $0.01 \pm 0.00$ & - & $0.03 \pm 0.00$ \\
\hline Night & $0.01 \pm 0.01$ & - & $0.03 \pm 0.00$ & - \\
\hline
\end{tabular}

Table 3: Average concentration pollutant with standard

\begin{tabular}{|c|c|c|c|c|}
\hline \multirow[b]{2}{*}{ Type of pollutants } & \multicolumn{3}{|c|}{ Sampling stations, $\min +$ S.D } & \multirow[b]{2}{*}{$\begin{array}{l}\text { Concentration (ppm) } \\
\text { (USECHH 2000) }\end{array}$} \\
\hline & PGC & LOKO & PPD & \\
\hline cyclohexane & $0.11+0.02$ & $0.01+0.01$ & $0.15+0.07$ & 300 \\
\hline n-hexane & $0.02+0.003$ & $0.01+0.002$ & $0.01+0.0$ & 50 \\
\hline Benzene & $0.05+0.01$ & $0.03+0.00$ & $0.06+0.03$ & 0.5 \\
\hline Toluene & $0.10+0.08$ & $0.06+0.03$ & $0.10+0.06$ & 50 \\
\hline
\end{tabular}

Table 4: Neurobehavioral performance among exposed workers and control

\begin{tabular}{|c|c|c|c|c|}
\hline Test & $\begin{array}{l}\text { Exposed respondents } \\
\text { Min } \pm \text { SP }\end{array}$ & $\begin{array}{l}\text { Controlled respondents } \\
\text { Min } \pm \text { SP }\end{array}$ & $\mathrm{t}$ - value & p-value \\
\hline Simple Reaction Time (SRT) & $51.09 \pm 13.16$ & $48.90 \pm 6.06$ & 0.62 & 0.54 \\
\hline Digit symbol (DS) & $47.41 \pm 8.99$ & $52.59 \pm 10.83$ & -1.52 & 0.14 \\
\hline Digit forward test (DFT) & $48.06 \pm 9.24$ & $51.94 \pm 10.92$ & -1.12 & 0.27 \\
\hline Digit backward test (DBT) & $49.85 \pm 9.99$ & $50.15 \pm 10.65$ & -0.09 & 0.93 \\
\hline Benton Visual Retention (BVR) & $48.26 \pm 12.27$ & $51.74 \pm 7.45$ & -1.00 & 0.33 \\
\hline $\begin{array}{l}\text { Santa Ana Manual Dexterity (SA) } \\
\text { dominant hand }\end{array}$ & $49.94 \pm 10.91$ & $50.06 \pm 9.67$ & -0.04 & 0.97 \\
\hline $\begin{array}{l}\text { Santa Ana Manual Dexterity* (SA) } \\
\text { non-dominant hand }\end{array}$ & $46.25 \pm 11.24$ & $53.75 \pm 7.50$ & -2.29 & 0.03 \\
\hline Santa Ana Manual Dexterity (SA) both hands & $49.78+9.99$ & $50.22 \pm 10.61$ & -0.13 & 0.91 \\
\hline Trail making test A (TMT) & $48.45 \pm 8.70$ & $51.55 \pm 11.48$ & -0.89 & 0.38 \\
\hline Trail making test $\mathrm{B}$ (TMT) & $50.48 \pm 10.88$ & $49.52 \pm 9.67$ & 0.27 & 0.79 \\
\hline Pursuit aiming test (PAT) $1 *$ & $54.22 \pm 11.45$ & $45.78 \pm 6.61$ & 2.63 & 0.01 \\
\hline Pursuit aiming test (PAT) 2 & $49.15 \pm 10.76$ & $50.85 \pm 9.76$ & -0.48 & 0.63 \\
\hline
\end{tabular}

$*$ : t-test $=\mathrm{p}<0.05$

Survey results found that only toluene possessed highest average concentration which was on morning shift, while different pollutant shows low concentration and no reading. These due to loco part's environmental circumstance exposed in environment air which reduces pollutant concentration in that area. From the schedule, diesel fuels pollutant did not exceed permitted standard. It means that the diesel fuels pollutant concentration was in low dose.

\section{WHO Neurobehavioral Core Test Battery (NCTB) 1986:}

Subjective symptom: Subjective symptoms between exposed workers and controlled group consist of 37 questions. Result found that there was no significant difference in subjective symptoms between exposed respondent compared to controlled group. This was caused by variety of factors which influenced among them such as age, duration of exposure and education level factors.
Neurobehavioral performance among workers: Table 4 shows average score derivative by exposed workers and control group. Through unpaired t-test carried out, achieved test difference neurobehavioral between exposed workers and control group only significant in Santa test Ana Manual Dexterity in hand that does not dominant namely $\mathrm{p}=0.03(\mathrm{p}<0.05)$ and Pursing Aiming test namely $\mathrm{p}=0.01(\mathrm{p}<0.05)$. This shows motor nerve achievement between exposed respondent with different control group.

NCTB relation with age, period serve and education level: Table 5 shows the relationship between NCTB test with age, period serve and education level. Through Pearson correlation' test carried out, found Benton Visual Retention test, Santa Ana Manual Dexterity for dominant hand and hand not dominant negative correlation with age namely $\mathrm{r}=-0.48, \mathrm{p}<0.05$. While different test did not show correlation with age. 
Am. J. Environ. Sci., 7 (3): 248-253, 2011

Table 5: Correlation NCTB between age, period serve and education level

\begin{tabular}{|c|c|c|c|c|c|c|c|c|c|c|c|c|c|}
\hline & & SRT & DS & DFT & DBT & BVR & SA 1 & SA 2 & SA 3 & TMTA & TMTB & PAT I & PAT 2 \\
\hline \multirow[t]{2}{*}{$\overline{\text { Age }}$} & (r) & $(-0.03)$ & $(-0.20)$ & -0.3 & $(-0.15)$ & $(-0.48)^{*}$ & $(-0.48)^{*}$ & $(-0.48)^{*}$ & $(-0.04)$ & -0.17 & -0.34 & -0.21 & $(-0.19)$ \\
\hline & p & 0.46 & 0.22 & 0.11 & 0.28 & 0.03 & 0.03 & 0.03 & 0.06 & 0.26 & 0.09 & 0.2 & 0.23 \\
\hline Service & (r) & -0.09 & $(-0.22)$ & -0.17 & -0.15 & $(-0.57)^{*}$ & $(-0.37)$ & $(-0.32)$ & $(-0.39)$ & -0.13 & $(0.54) *$ & $(0.42)^{*}$ & -0.04 \\
\hline Period & $\mathrm{p}$ & 0.37 & 0.19 & 0.25 & 0.28 & 0.01 & 0.06 & 0.11 & 0.05 & 0.3 & 0.01 & 0.04 & 0.43 \\
\hline Educational & (r) & -0.04 & -0.16 & -0.3 & -0.11 & -0.35 & $(0.49)^{*}$ & $(0.48)^{*}$ & -0.41 & $(-0.17)$ & $(-0.40)$ & $(-0.21)$ & $(-0.05)$ \\
\hline Level & $\mathrm{p}$ & 0.44 & 0.26 & 0.11 & 0.33 & 0.08 & 0.02 & 0.02 & 0.05 & 0.25 & 0.05 & 0.2 & 0.42 \\
\hline
\end{tabular}

Table 6: Correlation pollutant and NCTB test

\begin{tabular}{|c|c|c|c|c|c|c|c|c|c|c|c|c|c|}
\hline \multicolumn{2}{|c|}{ Concentrations } & SRT & DS & DFT & DBT & BVR & SA 1 & SA 2 & SA 3 & TMTA & TMTB & PAT I & PAT2 \\
\hline \multirow[t]{2}{*}{ Cyclohexane } & $(\mathrm{r})$ & $(-0.08)$ & $(-0.26)$ & $(-0.06)$ & $(-0.06)$ & $(-0.72)$ & $(-0.03)$ & $(-0.27)$ & $(-0.53)^{*}$ & -0.12 & -0.07 & -0.11 & -0.01 \\
\hline & $\mathrm{p}$ & 0.37 & 0.17 & 0.47 & 0.41 & 0.24 & 0.45 & 0.17 & 0.02 & 0.33 & 0.41 & 0.34 & 0.48 \\
\hline \multirow{2}{*}{ n-Heksana } & (r) & -0.06 & $(-0.14)$ & $(-0.17)$ & $(-0.35)$ & $(-0.10)$ & $(-0.31)$ & $(-0.30)$ & $(-0.27)$ & $(-0.03)$ & -0.02 & $(-0.24)$ & $(-0.32)$ \\
\hline & $\mathrm{p}$ & 0.41 & 0.31 & 0.28 & 0.09 & 0.36 & 0.12 & 0.14 & 0.16 & 0.46 & 0.47 & 0.19 & 0.12 \\
\hline \multirow[t]{2}{*}{ Benzena } & (r) & -0.27 & $(-0.57)^{*}$ & -0.08 & $(-0.03)$ & $(-0.02)$ & $(-0.54)^{*}$ & $(-0.36)$ & $(-0.64)^{*}$ & -0.06 & -0.24 & -0.08 & $(-0.14)$ \\
\hline & $\mathrm{p}$ & 0.17 & 0.01 & 0.39 & 0.45 & 0.47 & 0.01 & 0.09 & 0.01 & 0.42 & 0.19 & 0.39 & 0.31 \\
\hline \multirow[t]{2}{*}{ Toluena } & (r) & $(-0.26)$ & $(-0.05)$ & -0.27 & $(-0.12)$ & $(-0.22)$ & $(-0.21)$ & $(-0.32)$ & $(-0.08)$ & $(-0.02)$ & $(-0.09)$ & -0.09 & -0.03 \\
\hline & $\mathrm{P}$ & 0.17 & 0.43 & 0.16 & 0.33 & 0.21 & 0.22 & 0.13 & 0.37 & 0.48 & 0.38 & 0.38 & 0.47 \\
\hline
\end{tabular}

*: Correlation $=\mathrm{p}<0.05$ )

Whereas for period serve show negative correlation between Benton Visual Retention test namely $r=-0.57$, $\mathrm{p}<0.05$ while positive correlation in Trail Making test $B$ part namely $\mathrm{r}=0.54, \mathrm{p}<0.05$ and Pursuit Aiming part one namely $\mathrm{r}=0.42, \mathrm{p}<0.05$. While different test did not show correlation with period serve. From revenue acquired shows the longer exposure towards pollutant can cause more loss of memory and reduce nerve function motor. Besides that, for positive correlation education level in Santa test Ana Manual Dexterity for dominant hand and hand not dominant namely $r=0.49$, $\mathrm{p}<0.05$ and $\mathrm{r}=0.48, \mathrm{p}<0.05$. This shows that workers with higher education level correlate better in the NCTB achievement.

According to Kiesswetter et al. (2000), ages was the main factor for neurobehavioral test. This shows on the increasingly rise of vulnerable age achievement in NCTB test. Whereas long term exposure closely related to duration of exposure (Kanga et al., 2005).

Relation of diesel fuels pollutant between NCTB tests: Table 6 shows relationship between pollutants with NCTB test. Through Pearson correlation test carried out, it is found that concentration n-hexane and toluene does not show relation with NCTB test.

For cyclohexane concentration, there are significant negative correlation for SA test 3 (second sides of hand) namely $r=-053, p<0.05$. While different test did not show the correlation with cyclohexane concentration. This show the longer exposure in cyclohexane will cause Santa tests achievement Ana Manual Dexterity second lesser hand split.
For benzene concentration there are strong negative correlation significant for DS test, SA 1 and SA 3 and respectively with value $r=-0.57,-0.54,-0.64$, $\mathrm{p}<0.05$. While different test did not show the correlation with concentration of toluene.

Many effects of neurology data as a result exposure to cyclohexane in man through exposure at workplaces because open hand, also by different chemical material mixture such as n-hexane and toluene (Kreckmann et al., 2000). Continuous benzene exposure in long run associated with distal neuropathic, sleeplessness and loss of memory (ASTDR, 2007). Apart from that, chronic exposure in low concentration also associated with effect on peripheral nervous system. Abnormal in information transfer system of motor nerve visible in individuals through exposed job in solvent which contains benzene.

\section{CONCLUSION}

TVOC concentration every sampling point are different and PGC record highest reading followed by Loco and PPD. Generally highest pollutant of average concentration in Depot Locomotive namely toluene and followed by cyclohexane, benzene and $n$-hexane. There are differences in NCTB series of test namely BVR test, SA1, SA2 and PAT1 with age, period serve and employee education level. Besides that, contact between pollutants namely concentration cyclohexane with SA test 3 and benzene with DS test, SA 1 and SA 3 . This study shows workers exposure towards diesel pollutant in industry. 
Am. J. Environ. Sci., 7 (3): 248-253, 2011

\section{REFERENCES}

ASTDR, 2007. Toxicological Profile Benzene (Update). Agency for Toxic Substances and Disease Registr. http://www.atsdr.cdc.gov/toxprofiles/tp3.html

Ahilan, T., K.P. Mohammed and S.A. Arumugham, 2009. Critical review of global wind power generation. Am. J. Applied Sci., 6: 204-213. DOI: 10.3844/ajassp.2009.204.213

DOSH, 2000. Assessment of the Health Risks Arising From the use of Hazardous Chemicals in the Workplace. Ministry of Human Resources Malaysia. http://www.ibs.upm.edu.my/note/garispanduan27.p df.

Guo, H., S.C. Lee, L.Y. Chan and W.M. Li, 2004. Risk assessment of exposure to volatile organic compounds in different indoor environments. Environ. Res., 94: 57-66. DOI: 10.1016/S00139351(03)00035-5

Kanga, S.K., D.S. Rohlmanb, A. Mi-Young Lee, A. HyeSil Lee and S.Y. Chunga et al., 2005. Neurobehavioral performance in workers exposed to toluene. Environ. Toxicol. Pharmacol., 19: 645-650. DOI: 10.1016/J.ETAP.2004.12.049

Kiesswetter, E., B. Sietmann, M. Zupanic and A. Seeber, 2000. Neurobehavioral study on the interactive effects of age and solvent exposure. Neurotoxicology, 21: 685-695. PMID: 1130272

Kreckmann, K.H., J.K. Baldwin and L.G. Roberts, 2000. Inhalation developmental toxicity and reproduction studies with cyclohexane. Drug Chemical Toxicol., 23: 555-73. DOI: 10.1081/DCT-100101971
Ming, H.Y., 2004. Environmental Toxicology. 2nd Edn., CRC Press, Boca Raton,ISBN: 156670670X, pp: 339.

Najafi, G., B. Ghobadian, T.F. Yusaf and H. Rahimi, 2007. Combustion analysis of a CI engine performance using waste cooking biodiesel fuel with an artificial neural network aid. Am. J. Applied Sci., 4: 759-767. DOI:10.3844/ajassp.2007.759.767

Saarela, K., T. Tirkkonen, J. Laine-Ylijoki, J. Jurvelin and M.J. Nieuwenhuijsen, 2003. Exposure of population and microenvironmental distributions of volatile organic compound concentrations in the EXPOLIS study. Atmospheric Environ., 37: 5563-5575.

DOI: 10.1016/J.ATMOSENV.2003.09.031

Song, C., S. Chang, Hsu and I. Mochida, 2000. Chemistry of Diesel Fuels. 1st Edn., Taylor and Francis, New York, ISBN: 1560328452, pp: 294.

Triebig, G. and J. Hallermann, 2001. Survey of solvent related chronic encephalopathy as an occupational disease in European countries. Occup. Environ. Med., 58: 575-581. DOI: 10.1136/oem.58.9.575

World Health Organization, 1986. Neurobehavioral Core Test Battery. Operational Guide. Office of Occupational Health, Geneva. http://www.who.int/peh-

emf/meetings/archive/en/proceedings_eng.pdf 